\title{
The toxic impact of local anaesthetics in menopausal women: causes, prevention and treatment after local anaesthetic overdose. Local anaesthetic systemic toxicity syndrome
}

\author{
Bogusław Sobolewski ${ }^{1}$, Paweł Doman ${ }^{1}$, Tomasz Stetkiewicz ${ }^{2}$, Przemysław Oszukowski ${ }^{3}$, Piotr Woźniak
}

${ }^{1}$ Polish Mother's Memorial Hospital Research Institute, Lodz, Poland

${ }^{2}$ Gynaecology and Gynaecologic Oncology Department, Polish Mother's Memorial Hospital Research Institute, Lodz, Poland

3Perinatology and Gynaecology Department, Polish Mother's Memorial Hospital Research Institute, Lodz, Poland

${ }^{4}$ Specialistic Outpatient Clinics, Polish Mother's Memorial Hospital Research Institute, Lodz, Poland

\begin{abstract}
Gynaecologists often use local anaesthetics in their medical practice. Some concomitant diseases during the menopausal period may cause problems during the qualification of postmenopausal women for general anaesthesia in gynaecological surgery. Many authors suggest the application of local analgesia for particular kinds of gynaecological surgery procedures performed on postmenopausal women, taking into consideration health determinants. While applying local anaesthetics, the possibility of their overdose has to be taken into account. Generalised toxic symptoms which appeared after the local anaesthesia are rare, but potentially are lethal complications. Toxic symptoms after local anaesthetic administration are manifested after accidental administration of a medicine into a blood vessel, when extravascular administration of a large volume of a local anaesthetic is absorbed into a bloodstream or with the reproducible doses of local anaesthetics which are administered when metabolism does not work sufficiently and cannot eliminate these substances. Clinical overdose of local anaesthetics is manifested by disorders in two systems. Firstly, the pathological symptoms come from the central nervous system (CNS). In the second phase, the pathological symptoms will additionally appear in the cardiovascular system. The aim of the present thesis is to remind clinical manifestations of the local anaesthetic overdose and suggest the management of patients with the aforementioned symptoms, especially in the case of intravenous lipid emulsions which have the status of an antidote in life-threatening conditions caused by cardiotoxic effects of local anaesthetics.
\end{abstract}

Key words: local anaesthetics, dosage, toxicity, pharmacokinetics, treatment, intravenous lipid emulsions, menopause.

\section{Introduction}

The menopause period is characterised by the lack of active estradiol. It results in multiple internal diseases. The most common abnormality diagnosed in the menopausal period is arterial hypertension. The typical organ complications of arterial hypertension are strokes, coronary artery disease, left-ventricle hypertrophy and heart failure. Obesity plays a particularly important role in postmenopausal women. According to the available national data, 2/3 of women after menopause have a raised body mass index (BMI), and obesity increases the risk of arterial hypertension up to 3-4 times [1]. In the menopause, different risk factors for venous thromboembolism are cumulating. The most typical characteristics for this period are: obesity, varicose veins, smoking, cardiac diseases, lower level of physical activity, malignant tumours, and meno- pausal hormone therapy [2]. In the menopausal period, different thyroid dysfunctions may appear, out of which the most problematic are subclinical forms of hyperthyroidism and hypothyroidism [3]. Both diseases are the reasons for homeostasis dysfunctions. These diseases, such as many other less serious or less frequent ones, may cause problems during the qualification of postmenopausal women for anaesthesia in gynaecological surgery. Many authors suggest the application of local analgesia for particular kinds of gynaecological surgery procedures performed on postmenopausal women, taking into consideration the aforementioned health determinants.

For the sake of a patient's comfort there is a possibility of performing minor surgeries under local anaesthesia on a vagina, vulva and cervix, as well as fractional dilation and curettage and hysteroscopy. Obviously, for

\footnotetext{
Corresponding author: dr hab. n. med, prof nadzw. ICZMP Tomasz Stetkiewicz, Gynaecology and Gynaecologic Oncology Department, Polish Mother's Memorial Hospital Research Institute, 281/289 Rzgowska St., 93-338 Lodz, Poland, e-mail: tstet@interia.pl

To cite this article: Sobolewski B, Doman P, Stetkiewicz T, Oszukowski P, Woźniak P. The toxic impact of local anaesthetics in menopausal women: causes, prevention and treatment after local anaesthetic overdose. Local anaesthetic systemic toxicity syndrome. Prz Menopauzalny 2015; 14: 65-70. Submitted: 18.09.2014; Accepted: 9.02.2015.
} 
the full comfort of patients these surgeries should be performed under general anaesthesia, but in many cases of postmenopausal women there are contraindications which arise from comorbid conditions. On the other hand, it is recommended to perform these surgical procedures on such patients for the sake of their lives.

Numerous cutaneous lesions are located in the region of female genital organs, occasionally presenting a diagnostic and therapeutic challenge. The most common cases include: eczema vulvae, lichen simplex chronicus, lichen sclerosus et atrophicus or lichen planus. Clinical presentation of these lesions is not always characteristic of certain dermatoses. Thus, it is important to conduct proper tests, including histopathological or contact allergy examinations. Only thorough diagnostic procedures make it possible to implement the correct therapy [4].

The absolute necessity to perform a surgery despite the contraindications for general anaesthesia arises for all anomalies in the vulva and vaginal part of the cervix and in the uterus which bring a suspicion of cancer. Even in local anaesthesia, it is vital to obtain the material in the form of the sections for histopathological evaluation in order to confirm or exclude the existence of a cancer.

Similar rules apply in the case of vaginal bleeding after the menopause, suspicious dark brown coloured leucorrhoea and the abnormal endometrium picture in the ultrasound scan. These symptoms may bring suspicions of a cancer which comes from the mucous membrane of the uterus, what urgently requires to obtain the material for histopathological examination by $D \& C$. Hysteroscopy enables control of the process of obtaining the material and, consequently, reduces the risk of exposing the patients to another surgery. With contraindications for general anaesthesia, these surgeries may be performed under local anaesthesia of uterine cervix plexus with additional sedation. In hysteroscopy under general anaesthesia it is preferable to use Bettocchi hysteroscopes.

The examples of either diseases of the postmenopausal period or types of surgical procedures performed suggest the application of local anaesthesia in order to perform gynaecological surgery in menopausal women. Nevertheless, in order to perform a surgery with dispatch and with full comfort both for the patient and for the gynaecologist, the knowledge of local anaesthetics, their dosage and a maximum dose, pharmacokinetics and possible complications after their overdose is necessary. The knowledge about the treatment of complications after an overdose of local anaesthetics is crucial as well.

Regional anaesthesia is getting more and more popular. Newer local anaesthetics and newer techniques of imaging the nerve and vessel tracts enable application of this type of analgesia. The ageing popula- tion in developed countries is an important factor, too. In the population of the elderly people who suffer from more chronic diseases than young people, this kind of anaesthesia is used more eagerly. It should be noted that frequent use of regional anaesthesia techniques increases the possibility of side effects prevalence, especially among elderly people. Local anaesthetics are used not only by anaesthesiologists, but they are also applied by doctors of other specialties, in particular by surgeons. Recent research conducted in Great Britain revealed that doctors who are not anaesthesiologists have insufficient knowledge about the local anaesthetic overdose and the treatment after the overdose. In order to portray the problem clearer, the research results are useful. They reveal that $50 \%$ of the surgeons do not know how to calculate an appropriate dose of a local anaesthetic, 93\% do not know what to treat local anaesthetic systemic toxicity (LAST) with, and only $3 \%$ know how much of the initial dose should be administered [5]. In Mayzner-Zawadzka's lectures on the LAST syndrome, there is information that the first toxic complications which are the cause of death appeared after bupivacaine application for a paracervical block in gynaecology.

Regional anaesthesia requires local anaesthetics which can be allocated to one of the two groups: amino esters - derived from esters (cocaine, benzocaine, procaine, amethocaine, chloroprocaine, tetracaine, novocaine) and amino amides - derived from amides (prilocaine, lidocaine, bupivacaine, mepivacaine, etidocaine, ropivacaine, levobupivacaine). All these drugs, in the case of their overdose, are potentially dangerous to health or even life. Local anaesthetic overdose may occur as a result of unintentional intravascular administration of a medicine or a systemic absorption of a medicine.

Two types of overdoses are distinguished: relative and actual overdose. A relative overdose occurs when a medicine is administered quickly and intravascularly, even when a dose is lower than the maximum dose limit. This kind of overdose is also feasible in medicine administration into a well vascularised region. The second type of overdose is called an absolute overdose and occurs when a dosage of a medicine exceeds the maximum acceptable dose - calculated per body weight.

\section{The aim of the thesis}

The aim of the thesis is to describe local anaesthetics which are widely used in gynaecological practice. The application of older local anaesthetics, such as lidocaine and bupivacaine, as well as newer ones - ropivacaine - requires detailed knowledge not only of their pharmacokinetics. Other equally important issues are knowledge of the dosage of these medicines, symptom identification consistent with local anaesthetic over- 
dose and the ability to treat life-threatening complications after a local anaesthetic overdose. The knowledge of a relatively new local anaesthetic, that is ropivacaine, seems to be particularly important, because it excels older local anaesthetics in many ways.

\section{The profile of the most widely applied local anaesthetics}

Currently the most widely applied local anaesthetics in Poland are lidocaine and bupivacaine. Lidocaine is used the most frequently. It has a fast onset of action within 3-5 minutes. Its duration of action is 45-60 minutes. The adrenaline addition in a concentration of $1: 200000$ extends the duration of action twice. The maximum dose of lidocaine is $5 \mathrm{mg} / \mathrm{kg}$, and with adrenaline $-7.5 \mathrm{mg} / \mathrm{kg}$. Bupivacaine has an onset of action within 5-20 minutes. Its duration of action is 3-10 hours. The adrenaline addition slightly extends the duration of action. The maximum dose of bupivacaine is $2-3 \mathrm{mg} / \mathrm{kg}$. Bupivacaine usually takes the form of a racemic mixture which contains $S$ and $R$ enantiomers. It was determined that $\mathrm{R}$ isomer has considerably bigger cardiotoxic properties. Cardiotoxicity of bupivacaine (especially its $\mathrm{R}$ isomer) became interesting for the scientists in order to devise a preparation of single enantiomers. Ropivacaine is chemically very similar to bupivacaine, but the only drug used in local anaesthesia is the S enantiomer solution. In a concentration which conforms with the potency of bupivacaine, it is far less toxic. It causes cardiac arrhythmia and is the reason for circulatory collapse far less often, and in the case of cardio-circulatory depression, resuscitation is more often effective. Ropivacaine is only slightly weaker and has shorter duration of action than bupivacaine, but in the case of applying the diluted solutions it induces a much stronger differentiating block. It is used in peripheral nerve blocks and in epidural anaesthesia, especially when administration of high doses of long-acting local anaesthetics is necessary [6].

Ropivacaine is a local anaesthetic from the amide class of the prolonged duration of action of both anaesthesia and analgesia. High doses of ropivacaine provide the anaesthetic effect in surgery. On the other hand, lower doses simultaneously induce sensory and limited, stable motor blocks.

The mechanism of the action focuses on a reversible reduction of the permeability of sodium ions through the outermost layer of the nerve fibre. As a result, the speed of depolarization is reduced and neuronal excitability threshold is increased, what raises local nerve impulse blockade. The most typical property of ropivacaine is its long duration of action. The administration of anaesthesia and the duration of an efficient action of a local anaesthetic depend on the site of administration and dose of a medicine. However, they do not depend on a vasoconstrictor (such as adrenaline).

\section{The mechanism of action of local anaesthetics}

The action of local anaesthetics consists in the production of a reversible block in peripheral nerves. To put it in another way, it is blocking the depolarization of the cell membrane in all excitable tissues. There is the resting potential between the inside of a cell and its surroundings which has a value of approximately $-70 \mathrm{mV}$. In consequence of the excitation of a nerve, there is a quick increase in the membrane potential up to approximately $+20 \mathrm{mV}$, and then the resting state is brought back immediately. The sequence depolarization/polarization lasts 1-2 ms and is a well-known sequence of the action potential related to the transmission of a nerve impulse. As a result of depolarization of nerve fibre there is a sudden increase in permeability through the cell membrane of sodium ions which diffuse according to a concentration gradient and electrochemical gradient. Sodium ions permeate to a cell through big protein molecules - channels integrated into a cell membrane, maintained in the resting phase. Nerve excitation changes a channel's configuration and opens it, what enables positive sodium ions to enter the cell. Consequently, the membrane potential increases up to approximately $+20 \mathrm{mV}$. After the electrochemical gradients and sodium concentration become balanced, the channels close up [6].

Local anaesthetics which are on the market are supplied as water soluble salts, usually hydrochlorides. These medicines contain non-ionized and cationic forms. Local anaesthetics permeate through a nerve cell membrane in a non-ionized form and then decompose in a cell to an ionized form which blocks a sodium channel, what prevents sodium ions from entering the cell. As a result, the action potential is not generated and cannot be transmitted - a transmission block is developing [7].

\section{The generalised toxicity of local andesthetic}

When a substantial quantity of local anaesthetic reaches the brain or heart, it produces the same effect of "membrane stabilization" as in a peripheral nerve, what leads to progressive depression of these organs. The earliest manifestation of the generalised toxicity of a local anaesthetic is numbness or tingling of the tongue and oral area; it stems from very good blood supply of these regions, thanks to what the sufficient amount of the anaesthetic gets there in order to influence nerve endings. Local anaesthetic overdose is manifested above all by the nervous system symptoms. Initially, due to the slow increase in the medicine concentration in blood, so called inhibitory nerve cells become blocked, what consequently induces an excitation effect. According to a dose, this condition may go into a nervous 
system depression which is caused by the blocking of all neurons by local anaesthetics [8]. Local anaesthetic overdose far less often and to a lesser extent leads to cardiovascular system symptoms, that is to drop in arterial blood pressure and cardiac arrhythmia [9].

\section{Causes of LAST}

Toxic symptoms after local anaesthetics administration are manifested:

- after accidental administration of a medicine into a blood vessel,

- when extravascular administration of a large volume of a local anaesthetic is absorbed into a bloodstream,

- with the reproducible doses of local anaesthetics which are administered when metabolism does not work sufficiently and cannot eliminate these substances.

\section{Factors favouring LAST syndrome}

The factors favouring the LAST syndrome include:

- the injection site (particularly well-vascularized human body regions are predisposed to the LAST syndrome when local anaesthetics are deposited inattentively; it concerns a cervical plexus block, brachial plexus block, intercostal nerve block, epidural space, Bier block anaesthesia or the mentioned uterine cervical region),

- local anaesthetics, their potency, binding capacity with proteins, the total dose, that is the volume and concentration, vasoactive properties (blood vessels constriction - ropivacaine, prilocaine; widening - lidocaine) or the vasoconstrictors, what enables the increase of the dose even by $100 \%$,

- individual factors, such as the age group, metabolic disorders (liver, kidneys), heart diseases with the drop of the ejection fraction, acidosis, hypoxia, hypercapnia, pregnancy, drugs interactions [10].

\section{Clinical picture of the LAST syndrome}

Generalised toxic symptoms which appeared after the local anaesthesia are rare, but are potentially lethal complications. They occur in 1/1000 cases of regional anaesthesia. In 1928, Meyer was the first to describe 40 cases of deaths of the patients who had regional anaesthesia [11]. Clinical overdose of local anaesthetics is manifested by the disorders in two systems. Firstly, the pathological symptoms come from the central nervous system (CNS). Along with the increase in the anaesthetic concentration, the following disorders in the plasma will occur:

- numbness of the tongue and lips,

- vertigo,

- tinnitus,
- blurred vision,

- speech disorder,

- spasms,

- loss of consciousness,

- generalised tonic-clonic convulsion,

- coma,

- apnoea.

In the second phase, the following pathological symptoms will additionally appear in the cardiovascular system:

- cardiac contractility degradation,

- cardiac arrhythmia,

- peripheral blood vessel widening and drop in arterial blood pressure,

- circulatory system depression,

- cardiogenic shock,

- ventricular fibrillation or asystole [12].

It should be pointed out that the clinical picture of the LAST syndrome in $40 \%$ of the cases has an atypical form. It is characterised by the delayed onset of symptoms (5-15 minutes, rarely 15-30 minutes), and with the continuous infusion techniques, the onset is delayed by even a few days from the moment of anaesthesia. The atypical forms can also include the toxicity symptoms which appear simultaneously in the CNS and cardiovascular system. And finally, the cardiological symptoms alone (which occur in patients who have general anaesthesia or get deep sedation) [13].

\section{Prevention and recommendations for the LAST treatment}

Until recently, the classic overdose treatment has been a standard life-saving procedure, sophisticated procedures (advanced cardiac life support - ACLS) in cardiopulmonary resuscitation - CPR. Nevertheless, this procedure often was not enough, especially in the case of bupivacaine cardiotoxicity. In that case, extracorporeal circulation ECC is necessary. Currently, in local anaesthetic overdose treatment, the use of lipid filler is allowable.

There is no one, efficient treatment method in LAST syndrome prevention. The best one is the prevention. The weakest and the least toxic medicines which achieve the desired result should be used. In order to prevent the onset of the systemic toxic symptoms, the dose of a medicine should be adjusted according to the age, weight and current comorbid conditions of a patient.

Intravenous access has to be provided before local anaesthetic administration in order to start standard patient monitoring and check medicine and CPR equipment availability. Availability of the equipment to maintain airway patency is also essential because, in the event of local anaesthetics overdose, quick intubation may be necessary. 
In order to avoid an overdose in regional anaesthesia administration, doctors should try to avoid vascular medicine administration and, if possible, use ultrasonographic imaging to confirm a needle localization before local anaesthetic injection. Aspiration has to be performed repeatedly, before and during local anaesthetic injection. It should be remembered that aspirated blood will enter a needle or catheter tubing after a longer moment. It should be noted that $2 \%$ of aspiration gives false negative results. After aspiration and before full dose injection, a patient should get a small test dose in order to check if any toxic symptoms appear. Full dose portioning with aspirations between the doses helps to make sure that while putting a block, a needle or a catheter did not move to a vessel. It is recommended to administer the portioned doses - 3-5 ml every 30-44 seconds.

While putting a block, it is important to monitor a patient and, if necessary, maintain verbal communication to recognise early symptoms of intravascular injection (tinnitus, metallic taste in the mouth, anxiety, weakness).

To prevent the systemic absorption of a local anaesthetic, it is possible to add a vasoconstrictor to its solution to delay this process. In order to achieve this, epinephrine is a medicine which is the most often applied medicine, although other vasoactive drugs may also be used. The additional advantage of epinephrine is that it increases the heart rate when a test dose is absorbed systemically [14].

\section{LAST syndrome treatment}

In the case of a suspicion of local anaesthetic overdose in a patient, the first step is stabilization of potential life-threatening factors. The maintenance of airway patency, prevention of a significant drop in blood pressure and cardiac arrhythmia treatment play a leading role here. Local anaesthetic overdose complications treatment which involves the CNS and cardiovascular system is still very controversial, because there is no cure for this. Symptoms which come from the CNS and are manifested by the convulsions are effectively treated with benzodiazepine and barbiturates. Recent reports indicate that the intravenous administration of $1 \mathrm{mg} / \mathrm{kg}$ of propofol and $2 \mathrm{mg} / \mathrm{kg}$ of sodium thiopental efficiently inhibit convulsions after a local anaesthetic overdose. In cardiac arrhythmia treatment, the application of antiarrhythmic agents from the IB class, such as phenytoin, mexiletine or tocainide should be avoided, because they intensify the toxicity.

Bretylium and amiodarone are recommended, although the benefits of their application in a treatment are still studied. The study performed on pigs which were laboratory overdosed with local anaesthetics has shown that CPR with vasopressin and epinephrine com- bination has a higher survival rate than the separate application of these medicines [15]. There is no information about human reaction. Some of the recent case studies have shown that the stimulation of a heart and extracorporeal circulation may increase the survival rate after long-lasting CPR [16]. Until recently, local anaesthetic overdose complications have often been lethal, because CPR was generally inefficient in cardiac arrest. Sometimes, the only way to save a patient was extracorporeal circulation [17]. The Korean studies have shown the efficiency of glucose, insulin and potassium boluses in cardiovascular collapse reversal after bupivacaine overdose [18].

In the case of a serious cardiovascular collapse caused by a large local anaesthetic overdose, Weinberg et al. have proved the efficiency of an intravenous lipid emulsion infusion in CPR after a cardiac arrest [19, 20]. The first efficient application of intravenous lipid emulsion (ILE) in CPR after a local anaesthetic overdose was described by Rosenblatt et al. in 2006 [21]. Due to the increasing number of the reported cases of the efficient ILE action in CPR, the Association of Anaesthetists of Great Britain and Ireland (AAGBI) has issued the official guidance. All anaesthesia work stations, where local anaesthetics are applied, are instructed to be supplied with the adequate lipid doses and the instruction for their use [22]. In 2009, the Polish Working Party of the Board of the Polish Anaesthesiology and Intensive Care Medicine Association indicated that it is necessary to have "immediate access to $20 \%$ lipid emulsion in all work stations where regional anaesthetics are applied (including a labour ward)" [23]. In CPR after a local anaesthetic overdose, lipid emulsion which contains intralipid $20 \%$ can be used [17]. The efficient application of other lipid emulsions, such as Medialipid and Liposyn III were also described [24, 25]. According to AAGBI, Intralipid should be administered during standard CPR procedures. Nevertheless, some authors who rely on the results of experimental research and case studies of the efficient emulsion application, recommend administering ILE in the case of symptoms of a toxic influence of local anaesthetics [22]. The recent guidelines of AAGBI concerning ILE dosage for cardiac arrest induced by local anaesthetic overdose were released in 2010:

- a $20 \%$ lipid emulsion administered as a $1.5 \mathrm{ml} / \mathrm{kg}$ of body weight within 1 minute,

- a simultaneous inclusion of a $20 \%$ lipid emulsion infusion of a $15 \mathrm{ml} / \mathrm{kg}$ per hour,

- if the hemodynamically efficient cardiac function does not recover, the bolus dose administration should be repeated at most twice, keeping 5 minutes' intervals between the doses ( 3 boluses altogether) and the continuation of an infusion with the infusion dose increase of a $20 \%$ lipid emulsion up to $30 \mathrm{ml}$ $\mathrm{kg}$ per hour after 5 minutes from the beginning of the infusion, 
- a $20 \%$ lipid emulsion infusion should be continued up to the moment of hemodynamic stability or the cumulative overdose - over a $12 \mathrm{ml} / \mathrm{kg}$,

- in the case of a treatment of local anaesthetics side effects, the application of propofol in the form of a lipid emulsion and lidocaine substitute for cardiac arrhythmia treatment [26].

\section{Conclusions}

In their medical practice, gynaecologists often use local anaesthetics. They are applied to both a group of women of childbearing age and a group of women of menopausal age. Both groups are subject to the overdose of these drugs, because of the deposition of the anaesthetic (uterine cervical regions are very vascularized). The second group of women is subject to the local anaesthetic overdose because of the frequent internal organ dysfunction (liver, kidneys), what results in slower metabolism and slower elimination of these anaesthetics.

So there is a group of people and gynaecological surgeries in which local anaesthesia is better than more complicated anaesthesia. In order to perform these surgeries it is necessary to administer local anaesthetics. Nevertheless, in order to apply these medicines, the knowledge of both the medicines and their dosage is required. It is important to remember that local anaesthetic administered to patients improperly results in very serious consequences for their health and lives. That is why the ability to diagnose the overdose and the knowledge of possible overdose treatment is crucial.

\section{Disclosure}

Authors report no conflict of interest.

\section{References}

1. Stachowiak G, Faflik U, Zając A, et al. Nadciśnienie tętnicze u kobiet w okresie menopauzy. Prz Menopauzalny 2008; 2: 96-101.

2. Stachowiak G, Stetkiewicz T. Choroba zakrzepowo-zatorowa w okresie menopauzalnym. Prz Menopauzalny 2010; 4: 212-216.

3. Matuszek B, Paszkowski T, Nowakowski A. Wybrane problemy tyreologiczne w okresie menopauzy - kiedy i jak leczyć? Prz Menopauzalny 2010; 2: 63-66.
4. Olek-Hrab K, Jenerowicz D, Osmola-Mańkowska A, et al. Wybrane dermatozy sromu. Ginekol Pol 2013; 84: 959-965.

5. Ciechanowicz S, Patil V. Lipid emulsion for local anesthetic systemic toxicity. Anesthesiol Res Pract 2012; 2012. Article ID: 131784.

6. Aitkenhead AR, Smith G, Rowbotham DJ. Anestezjologia. Tom 1. Elsevier Urban \& Partner, Wrocław 2008.

7. Hadźić A, Vloka JD. Blokady nerwów obwodowych. Zasady i praktyka. Medipage, Warszawa 2008.

8. Krasny K, Wanyura H, Mayzner-Zawadzka E, Kołacz M. Nagłe przypadki w praktyce stomatologicznej. Reakcja na preparaty znieczulenia miejscowego. Czas Stomat 2005; 63: 129-134.

9. Barash PG, Cullen BF, Stoelting RK. Clinical Anesthesia. J. B. Lippincott Company, Philadelphia 1989.

10. Mulroy MF, Hejtmanek MR. Prevention of local anesthetic systemic toxicity. Reg Anesth Pain Med 2010; 35: 177-180.

11. Burch MS, McAllister RK, Meyer TA. Treatment of local-anesthetic toxicity with lipid emulsion therapy. Am J Health Syst Pharm 2011; 68: 125-129.

12. van der Nest L. Anaesthetics. Local anaesthetic agent systemic toxicity. CME 2012; 30.

13. Di Gregorio G, Neal JM, Rosenquist RW, Weinberg GL. Clinical presentation of local anesthetic systemic toxicity: a review of published cases, 1979 to 2009. Reg Anesth Pain Med 2010; 35: 181-187.

14. Marcucci C, Cohen NA, Metro DG, Kirsch JR. Zapobieganie najczęstszym błędom w praktyce anestezjologicznej. MediPage, Warszawa 2010; 561-563.

15. Mayr VD, Raedler C, Wenzel V, et al. A comparison of epinephrine and vasopressin in a porcine model of cardiac arrest after rapid intravenous injection of bupivacaine. Anesth Analg 2004; 98: 1426-1431.

16. Goldfrank LR, Flomenbaum NE, Lewin NA, et al. Goldfrank's Toxicologic Emergencies. Wyd. 6. McGraw-Hill, New York 1998; 897-903.

17. Nelson LS, Lewin N, Howland M, et al. Goldfrank's toxicologic emergencies. McGraw-Hill, New York 2011.

18. Kim JT, Jung CW, Lee $\mathrm{KH}$. The effect of insulin on the resuscitation of bupivacaine-induced severe cardiovascular toxicity in dogs. Anesth Analg 2004; 99: 728-733.

19. Weinberg GL, VadeBoncouer T, Ramaraju GA, et al. Pretreatment or resuscitation with a lipid infusion shifts the dose-response to bupivacaine-induced asystole in rats. Anesthesiology 1998; 88: 1071-1075.

20. Weinberg G, Ripper R, Feinstein DL, Hoffman W. Lipid emulsion infusion rescues dogs from bupivacaine-induced cardiac toxicity. Reg Anesth Pain Med 2003; 28: 198-202.

21. Rosenblatt MA, Abel M, Fisher GW, et al. Successful use of a $20 \%$ lipid emulsion to resuscitate a patient after a presumed bupivacaine-related cardiac arrest. Anesthesiology 2006; 105: 217-218.

22. Klimaszyk D, Kluzik A. Dożylne emulsje tłuszczowe w stanach zagrożenia życia. Anestezjologia i Ratownictwo 2012; 6: 53-57.

23. Mayzner-Zawadzka E, Kruszyński Z, Gaca M, et al.; Grupa Robocza Zarządu Głównego PTAilT. Analgezja zewnątrzoponowa porodu - wytyczne. Anestezjol Intens Ter 2009; 2: 114-118.

24. Ludot $H$, Tharin JY, Belouadah $M$, et al. Succesful resuscitation after ropivacaine and lidocaine-induced ventricular arrhythmia following posterior lumbar plexus block in a child. Anesth Analg 2008; 106: 1572-1574.

25. Warren JA, Thoma RB, Georgescu A, Shah SJ. Intravenous lipid infusion in the successful for local anesthetic-induced cardiovascular collapse after supraclavicular brachial plexus block. Anesth Analg 2008; 106: 1578-1580.

26. http://www.aagbi.org/sites/default/files/la_toxicity_2010_0.pdf. 